now restrains me from stating what may have been the -operating causes which produced the physiological effects observed by Dr. Sloan and attributed by him to the influence of high-frequency currents.

I do not concede that the only difference between Dr. Sloan and myself relates to my experiments with a vacuum tube for the production of ultra-violet rays, and I certainly disagree with him when he states in his article that his researches justify him in looking towards the future of electro-therapeutics with more confidence than ever and with the conviction that we are only now on the fringe of great possibilities. I am, Sirs, yours faitbfully,

Cardiff, Sept. 30th, $1907 . \quad$ J. CuNNINGHaM Bowie.

** This correspondence must now cease.-ED. L.

\section{THE REPORT ON MIDWIVES: A CORRECTION.}

\section{To the Elitors of THE LANOET.}

SIRs, - I am asked by the chairman of the subcommittee of the Association for Promoting the Training and Supply of Midwives, which drew up the report on midwives, published in ThE LANCET of July 20th, p. 178, to write to you with reference to an inaccuracy to which his attention has just been directed and which, as it might possibly give rise to some misunderstanding, he much regrets. In the paragraph headed "Number of Midwives Retiring," it is stated that a large majority (the figures being given) of practising midwives in the various counties aamed had, at the date mentioned, expressed their intention of ceasing to practise. The words should have been, "had sent in no notice of their intention to continue to practise." Will you kindly insert this correction? I am, Sirs, yours faithfully,

Westminster, S.W., Oet. 1st, $1907 . \quad$ R. V. GLLL, Secretary.

\section{ETHER INHALATION IN PULMONARY TUBERCULOSIS. \\ To the Editors of THE LANCET.}

SiRs,-Surely Dr. R. H. Hodgson cannot seriously mean what he writes in his letter appearing in your issue of Sept. 28th. He states: "I fully agree that anæsthesia for operations upon phthisical subjects is not desirable ....." Such a statement is so utterly absurd that it would be grossly unfair to phthisical patients if no anæsthetist were to take up the challenge. Patients with even very advanced pulmonary tuberculosis may generally be safely anæsthetised for an operation if due care be given to the choice of drug and the mode of administration. I have little doubt that every anæathetist will agree with me in saying that chloroform (or a mixture containing it) should be chosen for advanced cases, especially if there be a history of hæmoptysis ; but in early and mild cases I frequently administer the ethy] chloride-ether-chloroform sequence, and $I$ have not heard of any harm having been caused thereby. The ether should not be persisted in for too long and cyanosis must be strenuously avoided.

As regards the employment of ether inhalation for the direct treatment of pulmonary tuberculosis I think there is ample room for a diversity of opinions provided its use be limited to early cases, but it seems to me very doubtful whether a patient will be found who will be willing to be fully anæsthetised by ether sufficiently frequently to destroy the bacilli. Possibly the daily etherisation with its attendant vomiting might destroy the patient first. I am, Sirs, yours faithfally, Rowland W. Colmum.

New Cavendish-street, W., Oct. 1st, 1907.

\section{EXCISION OF THE PAROTID GLAND WITH PRESERVATION OF THE FACIAL} NERVE.

To the Editors of THE LANCET.

SIRS, - I was much interested in Mr. T. Carwardine's paper in THE LANCET of Sept. 28th on Excision of the Parotid. Gland with Preservation of the Facial Nerve, as in June, 1906, I had to deal with a similar case to his, and, like him, found that there were no cases recorded in which this procedure had been successfully carried out.

The patient, a lady of about 45 years, consulted me for a small tumour growing in the right parotid gland; on removal this proved to be a carcinoma. I advised the complete removal of the parotid gland, but warned my patient that such an operation might be followed by the complete paralysis of the facial muscles, as judging from all the literature I could obtain the preservation of the facial nerve seemed almost an impossibility. As two lymphatic glands could be felt under the angle of the jaw I tied the external carotid artery high up and cleared away the glands. I hoped by this procedure to render the removal of the parotid gland a comparatively bloodless operation and in doing so facilitate the dissection of the facial nerve. My hopes in this respect were not realised as the bleeding was all through rather free. 40 minutes' care ful work sufficed to preserve all the main branches of the nerve and to remove the entire gland. There was almost complete paralysis of the lower half of the face for the first five days, then this rapidly began to disappear, and five weeks after the operation the most careful extmination failed to show any difference between the two sides of the face. 15 months have now elapsed since the operation, and as there is no sign of recurrence I hope the patient is cured, as my experience of partial operations on carcinomatous growths in the parotid is most unfavourable, the disease growing again in a very few months in every case.

While I feel that the result in my case of almost immediate restoration of function to the whole facial nerve was too good not to have some element of good fortune in it, yet I think that we are justified in promising a patient that complete removal of the parotid gland can be done and a fair amount of facial movement will remain after such an operation. I am, Sirs, yours faithfully,

Dublin, Oct. 1st, 1907 LEVESON GOWER GUNN.

\section{TUBERCULIN FOR DIAGNOSIS.}

\section{To the Editors of THE LANCET.}

SIRS,-Can any of your readers tell me where $I$ can find details (practical details) and results of the method of diagnosis for tuberculous conditions which depends on the local inoculation of tuberculin? The tuberculin is rubbed into a small scarification of the skin and in the taberculous produces a pustule, scc., and in the non-tuberculous no effect. Can you tell me wherher there are any bad symptoms-temperature, lighting up of old disease, \&o.? How long do the pustules take to form? and what tuberculin is used? I presume the old tuberculin (original Koch). I have searehed. but cannot find any details of the method in the literature I have available. Thanking you in anticipation,

I am, Sirs, yours faithfully,

Hull, Sept. 25th, 1907. EDWARd Turton.

\section{THE WORKMEN'S COMPENSATION ACT, 1906.}

To the Editors of THE LANCET.

SIRs,-Although the medical man who has expressed an opinion upon the condition of an injured workman and who finds that his opinion is to be submitted to a medical referee may reasonably feel that he ought to be present when the medical referee examines the patient, in order to call attention to the symptoms upon which he has based his views, and to give reasons for his conclusions, it seems difficult to say with confidence that the regulations which your correspondent approves will bear the interpretation that this procedure is contemplated by the Home Office. There is a side to the question which cannot be ignored and on which you touch in your leading article The Workmen's Compensation Acts have been framed with a view to providing for the workman during incapacity through accidental injuries as cheaply and as expeditiously as possible. They may not be altogether successful in doing so, but at all events they are not intended to place the employed at any disadvantage when claimiug against his employer, or to favour the longest purse. In many trades or industries the injured workman belongs, almost without exception, to an organisation which can pay for the attendance of his medical man before the official referee, but the latest Act includes practically every class of employment and a vast number of workers who, at present at all events, will have to fight their claims, if contested, for them. selves. There is also the point of view of the medical referee who, while desiring to extend every courtesy to the members of his profession, and to weigh their opinions 